\title{
Assessment of Aspect Based Multidimensional Poverty in Urban Haryana
}

\author{
Nitin Tanwar ${ }^{* 1}$, Ekta Hooda ${ }^{1}$, B.K. Hooda ${ }^{1}$, P. K. Nimbrayan ${ }^{2}$ and Kavalpreet Kaur ${ }^{3}$ \\ ${ }^{1}$ Department of Mathematics \& Statistics, CCS HAU, Hisar, Haryana, India \\ ${ }^{2}$ Department of Agricultural Economics, CCS HAU, Hisar, Haryana, India \\ ${ }^{3}$ Department of Economics, Punjab University, Chandigarh, India \\ *Corresponding author: nitintanwar5@gmail.com
}

\begin{abstract}
Purely monetary approach to poverty measurement does not provide a true picture of deprivations or wellbeingness of households. Aspects based poverty measurement using multiple dimensions of deprivation gives a more complete picture of poverty. In this investigation, the Multidimensional Poverty Index (MPI) has been used to study deprivations experienced in multiple dimensions of drinking water, sanitation and housing facilities in urban Haryana. For estimation of the poverty across the urban areas of Haryana, household level secondary data from $69^{\text {th }}$ round of NSSO survey on selected indicators of drinking water, sanitation and housing facilities have been used. Based on MPI estimates the urban households in the district of Mewat have been found to be most deprived in reference to drinking water, sanitation and housing facilities in urban Haryana followed by Fatehabad, Rohtak, Mahendragarh, Jhajjar and Ambala.

Highlights

0 Multidimensional poverty index at district level has been calculated using selected indicators of aspects drinking water, sanitation and housing facilities in urban Haryana.
\end{abstract}

Keywords: Poverty measurement, Aspects based poverty, Multidimensional Poverty Index, Sanitation and housing facilities, urban areas

Poverty is defined by several countries in the world as scarcity of income. However, individuals who are poor themselves observe their experience of poverty considerably more extensively. An individual who is poor can experience the ill effects of many disadvantages in the meantime such as they may have lack of access to clean drinking water, lack of educational achievements, poor sanitation facilities, poor primary healthcare facilities, lack of electricity, child malnourishment, poor housing conditions, unhygienic conditions, unemployment etc. So income alone is not enough indicators to explain the true picture of multidimensional poverty.

Therefore, it is necessary for all the indicators from household's basic needs to be included in the analysis of multidimensional poverty. To make a more clearly comprehensive picture of poverty, the multidimensional poverty measures are utilized. These measures of multidimensional poverty analyzed the level of deprivation of the households and revealed that who is poor and how they are poor. The estimation of the poverty with the multidimensional scale provides wider and deeper view of wellbeing and could be efficiently used for the targeted policy interventions. Sen (1985) pointed out that the study of poverty should identify and analyze attributes than monetary which directly influence the individual welfare. The theoretical debate on the estimation of poverty in the past few years has led to the shift from the traditional unidimensional view of poverty to the new multidimensional concept of social exclusion (Hagenaars, 1986; Dagum, 1989; Sen, 1992).

The MPI assesses the nature and intensity of poverty 
DP Tanwar et al.

at the household level, with poor households being those who are multidimensionally deprived and the extent of their poverty being measured by the extent of their deprivations. The MPI creates a vivid picture of household living in poverty within and across countries, regions and the world. It is the first international measure of its kind, and offers an essential complement to income poverty measures because it measures deprivations directly.

The multidimensional poverty index (MPI) is the product of two measures, multidimensional headcount ratio $(\mathrm{H})$ and intensity of poverty (A) (Alkire and Foster, 2011). Here MPI was computed with comprising the indicators from the aspects of drinking water facilities, sanitation facilities and housing facilities for urban areas in Haryana. The multidimensional headcount ratio is the proportion of multidimensional poor to the total population. The intensity of poverty is the average weight of deprivations experienced by the multidimensionally poor at a time. Mohanty (2011, 2012) used the unit level data from NFHS-3 and linked multidimensional poverty with health and health care utilisation. Children belonging to multidimensional poor households are more likely to be deprived of health care and lower survival. De and Dutta (2014) made an attempt to measure the Multidimensional Poverty Index of Toto community in Jalpaiguri district of West Bengal. Poverty was measured in Human Development Reports through the Human Poverty Index (HPI) from 1997-2009. In 2010, the MPI replaced the HPI. The MPI addresses the imperfections of HPI by allowing comparisons across countries or regions of the world, as well as within-country comparisons between regions, ethnic groups, rural and urban areas. The MPI reveals the combination of deprivation that strikes a household at the same time. A household is considered as multidimentionally poor if it is deprived in some combination of indicators whose weight sum is 30\% or more of the dimension.

Tanwar and Hooda (2017) analyzed the deprivation profiles of rural households in Haryana to identify who is poor by constructing a MPI. They found that the districts Mewat, Rohtak, Palwal, Jhajjar and Fatehabad have higher value of MPI and indicating high level of poverty while districts Rewari, Kaithal, Bhiwani, Mahendragarh, Kurukshetra, Faridabad and Ambala were found in better condition.
Sharma and Vashishth (2017) made an attempt to explore the poverty in Haryana and also explore the inequality in deprivation of basic standard of living among the various districts of Haryana. The study gives a comparative picture of all the districts in terms of 8 selected standard of living indicators. It reveals wide disparities among the districts in Haryana. Strotmann and Volkert (2018) explored the combination of the capability and subjective well-being approaches. They analyzed multidimensional poverty by using micro data covering more than 2300 individuals from four villages in rural Karnataka and found positive correlations between multidimensional poverty index and lack of happiness. This paper probes into the scenario of access to facilities of drinking water, sanitation and housing in urban Haryana. Methodology developed by Alkire-Foster in 2011 has been applied for estimation of the aspect based multidimensional poverty of households in urban Haryana.

\section{MATERIALS AND METHODS}

\section{Data}

The data on selected indicators of $69^{\text {th }}$ round survey (2012) of NSSO on drinking water, sanitation, hygiene and housing condition in India have been used for the estimation of poverty in urban Haryana. A 'state sample' was surveyed by state government official wheareas the 'central sample' was surveyed by NSSO. Number of fsu's (villages/blocks) surveyed for schedule 1.2: NSS $69^{\text {th }}$ round, central sample for Haryana state 76 for rural and 72 for urban area. Second-stage units: For this particular survey, from each sample village and urban block, 12 households were selected respectively for canvassing schedule 1.2. The total numbers of 1756 households were considered from Haryana out of which 912 in rural Haryana and 844 in urban Haryana. In this study only urban households were studied for estimating aspect based multidimensional poverty in urban Haryana.

In measuring the multidimensional poverty three aspects viz. drinking water, sanitation and housing condition have been considered. These aspects comprise a total of ten indicators. The description of aspects and indicators is given in Table 1. Three indicators are related with the drinking water 
Table 1: The aspects, indicators and deprivation thresholds

\begin{tabular}{|c|c|c|}
\hline Aspect & Indicators & Deprived if... \\
\hline \multirow{3}{*}{$\begin{array}{l}\text { Drinking } \\
\text { water }\end{array}$} & Principal source of drinking water & $\begin{array}{l}\text { The household does not have Principal source of drinking water in the } \\
\text { dwelling/yard/plot }\end{array}$ \\
\hline & Whether drinking water sufficient & $\begin{array}{l}\text { The household does not have sufficient drinking water throughout the } \\
\text { year }\end{array}$ \\
\hline & $\begin{array}{l}\text { Distance of the principal source of } \\
\text { drinking water }\end{array}$ & $\begin{array}{l}\text { Principal source of drinking water is outside the premises more than } 0.2 \\
\text { K.M. }\end{array}$ \\
\hline \multirow{2}{*}{ Sanitation } & Access to latrine & $\begin{array}{l}\text { Household does not have exclusive use or Household use common } \\
\text { latrine in a building or public/community latrine }\end{array}$ \\
\hline & Facility of Bathroom & Household does not have bathroom \\
\hline \multirow{5}{*}{$\begin{array}{l}\text { Housing } \\
\text { facilities }\end{array}$} & Condition of structure & Household has bad condition of structure \\
\hline & Type of dwelling & The household does not have independent or own house \\
\hline & Floor type & The household has a mud, bamboo, wood lime stone floor \\
\hline & Wall type & $\begin{array}{l}\text { The household has bamboo/straw/reeds/grass, mud/unbrunt bricks and } \\
\text { other katcha walls }\end{array}$ \\
\hline & Roof type & $\begin{array}{l}\text { The household has bamboo/straw/reeds/grass, mud/ unbrunt bricks, } \\
\text { canvas/cloth and other katcha roof }\end{array}$ \\
\hline
\end{tabular}

dimension two with the sanitation dimension and five with the housing condition.

\section{Methods}

\section{Head Count Ratio}

Head count ratio is one of the most widely used poverty measure. It is also known as poverty Ratio (PR). The Head Count Ratio (HCR) measures the proportion of the population that is counted as poor. It gives the proportion of population which is not above the poverty line. It can be formally defined as:

$$
H C R=\frac{P}{N}
$$

Where, $P$ is the number of poor people and $N$ is the total population.

Poverty ratio is, thus, simply a head count ratio and it only measures the incidence of poverty. Though it is most commonly used measure of poverty, it suffers from the drawback that it does not take into account the level of poverty within poor people. Poverty ratio is not affected by upward or downward movement of poor people unless they cross the poverty line (Srivastava, 2009).

\section{Multidimensional Poverty Index (Alkire-Foster method, 2011)}

In unidimensional analysis, identification is normally accomplished by the use of a poverty line or threshold value. A poor household is one whose resource or achievement variable level falls below the poverty line.

In multidimensional setting, where there are multiple variables, identification of poor household is more challenging exercise. The multidimensional poverty index (MPI) developed by Alkire and Foster is a dual cut-off method, meaning that it identifies individuals who are deprived in each dimension and those who are multidimensionally poor. At the first stage, people with achievements below a "deprivation" threshold in each indicator are identified as deprived or non-deprived in that indicator. Then a second cross-dimensional "poverty" cutoff is applied. This cutoff represents the minimum percentage of weighted deprivations that a person must be deprived in to be considered multidimensionally poor. It is based on the counting approach and used different factors to measure poverty beyond income-based lists. For example, in the analysis of multidimensional poverty using Alkire-Foster method on the two aspects, each aspect have same weight in such a way that each aspect receives a $1 / 2$ weight. The indicators within each aspect are also equally weighted. So, every variable in the aspects of drinking water facilities and hygienic conditions takes a 1/10 weight.

\section{The poverty cut-off (Identification of the MPI based poor households)}

In accordance to every indicator chosen to measure 
the poverty every household is allocated a deprivation score as stated to its level deprivations. The calculation of deprivation scores for every household by taking a weighted sum of the deprivations experienced. The score of deprivation for every household are ranges between 0 and 1 . The score of deprivation and the levels of deprivation of the households are proportional to each other. If levels of deprivation of the households are increases then the score of deprivation also increases. If the levels of deprivation increases and achieves it's most extreme of 1 it means the household is deprived in every attribute chosen to poverty measurement. A household, which is not poor in any of the attributes, achieves a score of deprivation equal to 0. Formally:

$$
c_{i}=w_{1} I_{1}+w_{2} I_{2}+\ldots \ldots w_{d} I_{d}
$$

where $I_{i}=1$ if the household is absolutely poor in attribute and $I_{i}=0$ otherwise, and $w_{i}$ is the weight attached to attribute with,

$$
\sum_{i=1}^{d} w_{i}=1
$$

A second cut-off or threshold is used to identify the multidimensionally poor, which in the AlkireFoster methodology is called the poverty cut-off. The poverty cut-ff is the share of deprivations a household must have in order to be considered poor, and denoted by $k$. Household is considered poor if its deprivation score is equal to or greater than the poverty cutoff, i.e. if $c_{i} \geq k$. For those households whose deprivation score is below the poverty cutoff, even if it is non-zero, their score is replaced by a ' 0 ' and any existing deprivations are not considered in the 'censored headcounts'. This step refers to censoring the deprivations of the nonpoor (Alkire and Foster 2011, Alkire et al., 2015). To differentiate the original deprivation score from the censored one, we use the notation $c_{i}(k)$ for the censored deprivation score. Note that if $c_{i}<k$, then $c_{i}(k)=0 . c_{i}(k)$ is the deprivation score of the poor household.

\section{Computing the MPI (Aggregation)}

The first partial index is the percentage of the population that is poor, or the multidimensional headcount ratio $\mathrm{H}$ and defined as:

$$
H=\frac{q}{n}
$$

where, $q$ is the number of poor households and $n$ is the total number of households.

The second is the average intensity A, which calculates the deprivation share for each poor household by dividing the deprivation count by $\mathrm{d}$, and then averages across all poor households and is defined as:

$$
A=\frac{\sum_{i=1}^{n} c_{i}(k)}{q}
$$

where $c_{i}(k)$, is the censored deprivation score of individual $i$ and $q$ is the number of households who are multidimensionally poor.

The MPI is defined as:

$$
M P I=H \times A
$$

\section{RESULTS AND DISCUSSION}

\section{Poverty profile on the aspect of drinking water facilities}

Table 2 presents district-wise estimates of proportion of households below poverty line regarding the facilities of drinking water in urban Haryana in reference to the following three indicators:

(i) Principal source of drinking water

(ii) Drinking water sufficiency

(iii) Distance of the principal source of the drinking water

The deprivation thresholds used in Table 2 for various drinking water facilities have been given earlier in Table 1. Considering the deprivation thresholds in Table 1, the head count ratios have been computed using equation (1) of materials and methods section.

An examination of district level estimates indicates wide range of variation in different drinking water indicators across districts. The condition of some districts in terms of drinking water indicators is such better than in other districts. The performance of all districts is varying on different aspects related to drinking water facility. 
In case of principal source of drinking water, about fifty three per cent of the urban households in the districts of Jhajjar were found deprived followed by the households in the districts of Bhiwani (58.3\%), Panchkula (50\%), Kaithal (50\%), Fatehabad (41.7\%) and Sonipat $(41.7 \%)$ while the urban households in the districts of Kurukshetra $(0.0 \%)$, Karnal $(0.0 \%)$, Jind (4.2\%), Mahendragarh (4.2\%), Rewari (8.3\%) and Yamuna Nagar $(12.5 \%)$ were found nondeprived.

Table 2: Estimates of district-wise proportion of deprived households on the aspect of drinking water facilities in urban Haryana

\begin{tabular}{cccc}
\hline Districts & $\begin{array}{c}\text { Principal } \\
\text { source of } \\
\text { drinking } \\
\text { water }\end{array}$ & $\begin{array}{c}\text { Drinking } \\
\text { water } \\
\text { sufficiency }\end{array}$ & $\begin{array}{c}\text { Distance of the } \\
\text { principal source } \\
\text { of drinking } \\
\text { water }\end{array}$ \\
\hline Rohtak & 0.375 & 0.000 & 0.375 \\
Palwal & 0.208 & 0.000 & 0.000 \\
Jhajjar & 0.583 & 0.000 & 0.500 \\
Jind & 0.042 & 0.000 & 0.000 \\
Mewat & 0.292 & 0.500 & 0.292 \\
Hisar & 0.208 & 0.000 & 0.167 \\
Panipat & 0.319 & 0.000 & 0.014 \\
Karnal & 0.000 & 0.000 & 0.000 \\
Sonipat & 0.417 & 0.042 & 0.083 \\
Fatehabad & 0.417 & 0.208 & 0.292 \\
Panchkula & 0.500 & 0.250 & 0.500 \\
Gurgaon & 0.146 & 0.167 & 0.135 \\
Bhiwani & 0.583 & 0.000 & 0.542 \\
Kaithal & 0.500 & 0.000 & 0.000 \\
Faridabad & 0.316 & 0.190 & 0.305 \\
Yamuna & 0.125 & 0.000 & 0.125 \\
Nagar & & 0.000 & 0.042 \\
Mahendragarh & 0.042 & 0.000 \\
Kurukshetra & 0.000 & 0.000 & 0.000 \\
Sirsa & 0.208 & 0.167 & 0.167 \\
Rewari & 0.083 & 0.042 & 0.083 \\
Ambala & 0.354 & 0.271 & 0.229 \\
\hline & & &
\end{tabular}

Regarding sufficiency of drinking water, fifty per cent of the urban households of the district of Mewat did not get sufficient drinking water from the principal source throughout the year and were found deprived followed by the districts of Ambala (27.1\%), Panchkula (25.0\%), Fatehabad (20.8\%),
Faridabad (19.0\%) and Sirsa (16.7\%) while the urban households of the districts of Kurukshetra, Mahendragarh, Yamuna Nagar, Kaithal, Bhiwani, Karnal, Panipat, Hisar, Jind, Jhajjar, Palwal and Rohtak had sufficient drinking water from the principal source throughout the year and were found non deprived.

On the other hand, about $54 \%$ of the urban households in the districts of Bhiwani were found deprived in respect to the distance to the principal source of drinking water followed by Jhajjar (50.0\%), Panchkula (50.0\%), Rohtak (37.5\%), Faridabad $(30.5 \%)$ and Mewat $(29.2 \%)$ and the urban households in the districts of Karnal, Kurukshetra, Jind and Palwal were found non poor. The households of the districts of Panipat (1.4\%), Mahendragarh (4.2\%), Rewari $(8.3 \%)$, Sonipat $(8.3 \%)$ and Yamuna Nagar $(12.5 \%)$ were found to be slightly deprived in respect to the distance to the principal source of drinking water.

The urban households of the districts of Karnal and Kurukshetra showed similarity with respect to all indicators while the urban households of the districts Jhajjar, Bhiwani and Panchkula were found to have dissimilarity likely on all the indicators related to drinking water facilities as given in Table 2.

\section{Poverty profile on the aspect of sanitation facilities}

World Health Organization (1990) defines the term sanitation as "the provision of facilities and services for the safe disposal of human urine and feces. The word 'sanitation' also refers to the maintenance of hygienic conditions, through services such as garbage collection and waste water disposal".

For healthy life of population the most essential component is the maintenance of hygienic conditions and availability of neat and clean sanitation facilities. Sanitation facilities provide a mean to secure human wellbeing by giving a better environment that will stop the transmission of diseases. Improved sanitation is a term utilize to classified levels of sanitation for observing purposes. If the people do not have access to sanitation facilities then it is necessary to give them bathroom facilities as well as latrine facilities immediately. 
Table 3: Estimates of district-wise proportion of deprived households on the aspect of sanitation facilities in urban Haryana

\begin{tabular}{ccc}
\hline Districts & Access to latrine & $\begin{array}{c}\text { Facility of } \\
\text { Bathroom }\end{array}$ \\
\hline Panchkula & 0.167 & 0.208 \\
Mewat & 0.521 & 0.542 \\
Yamuna Nagar & 0.167 & 0.042 \\
Palwal & 0.292 & 0.125 \\
Sirsa & 0.208 & 0.083 \\
Gurgaon & 0.000 & 0.000 \\
Kurukshetra & 0.250 & 0.083 \\
Jhajjar & 0.250 & 0.167 \\
Ambala & 0.250 & 0.042 \\
Sonipat & 0.208 & 0.042 \\
Rohtak & 0.208 & 0.042 \\
Rewari & 0.227 & 0.000 \\
Fatehabad & 0.333 & 0.208 \\
Mahendragarh & 0.514 & 0.097 \\
Karnal & 0.083 & 0.000 \\
Bhiwani & 0.458 & 0.417 \\
Panipat & 0.167 & 0.083 \\
Hisar & 0.250 & 0.000 \\
Jind & 0.250 & 0.000 \\
Kaithal & 0.287 & 0.121 \\
Faridabad & 0.083 & 0.000 \\
\hline
\end{tabular}

Table 3 presents district-wise estimates of proportion of households below poverty line regarding the facilities for sanitation in urban Haryana in reference to the following three indicators:

\section{Access to Latrine}

\section{Facility of Bathroom}

The deprivation thresholds used in Table 3 for sanitation facilities have been given earlier in Table 1. Considering the deprivation thresholds in Table 1 , the head count ratios have been computed using equation (1) of materials and methods section.

Table 3 presents the estimates of district-wise proportion of deprived households on the aspect of sanitation facilities (access to latrine and facility of bathroom) in the urban areas of Haryana. After defining the deprivation threshold for these indicators we have calculated head count ratios. Analysing the levels of two sanitation facilities separately, the Table 3 revealed that, about fifty two per cent of the households in the urban areas of the district of Mewat were found deprived followed by the households in the districts of Mahendragarh $(51.4 \%)$, Bhiwani (54.8\%), Fatehabad (33.3\%), Palwal $(29.9 \%)$ and Kaithal $(28.7 \%)$. The households in urban areas of the district Gurgaon $(0.00 \%)$ were found completely non-deprived whereas the households in the districts of Faridabad (8.3\%), Karnal (8.3\%), Panchkula (16.7\%), Yamuna Nagar $(16.7 \%)$ and Panipat (16.7\%) were found to be slightly deprived on this indicator.

It was also observed that with regard to bathroom facility, $54.2 \%$ of the urban households in the districts of Mewat were found deprived followed by Bhiwani (41.7\%), Fatehabad (20.8\%), Panchkula (20.8\%), Jhajjar (16.7\%) and Palwal (12.5\%). The urban households of the districts of Gurgaon, Faridabad, Jind, Hisar, Karnal and Rewari had better bathroom facilities.

\section{Poverty profile on the aspect of housing facilities}

Everybody has the right to proper housing, which says something beyond four walls and a rooftop over one's head. Preventing from worst weather and climatic conditions, housing is much needed for essential basic needs. House is that place where people can rest and sleep, where they are free from any hazards or other type of risks. Moreover, for people's privacy, personal space and security, housing should be appropriate for them. Households with low incomes specially those who have low budget for making up a housing costs because of their other needful consumption as like food, education and medicinal services. The major facts of poor housing quality for health status i.e. lack of proper sanitation, functional utilities, condition of structure and insufficient number of rooms per person, who affected the physical and mental health of the people. The conditions of structure, type of dwellings, house tenure, building material for flooring, walls and roof and surrounding environment are the parts of housing conditions. The main fact of well-being and standards of living are the cost and quality of any housing.

On the analysis of housing quality with different five indicators, it can be stated from Table 4 that about $44 \%$ of the urban households in the district of Mewat were found deprived because they were 
living in bad condition of structure followed by the households in the districts of Fatehabad (41.7\%), Panipat (25.0\%), Sonipat and Rohtak with 20.8\%, Yamuna Nagar, Jhajjar \& Palwal with $16.7 \%$. While the urban households of the districts of Karnal, Kaithal, Kurukshetra, Jind, Sirsa and Mahendragarh were found non-deprived because of they were living in a good condition of structure.

Table 4: Estimate of district-wise proportion of deprived households on the aspect of housing facilities in urban Haryana

\begin{tabular}{cccccc}
\hline Districts & $\begin{array}{c}\text { Condition } \\
\text { of } \\
\text { structure }\end{array}$ & $\begin{array}{c}\text { Type of } \\
\text { Dwelling }\end{array}$ & $\begin{array}{c}\text { Floor } \\
\text { Type }\end{array}$ & $\begin{array}{c}\text { Wall } \\
\text { Type }\end{array}$ & $\begin{array}{c}\text { Roof } \\
\text { Type }\end{array}$ \\
\hline Mewat & 0.444 & 0.028 & 0.139 & 0.000 & 0.014 \\
Fatehabad & 0.417 & 0.000 & 0.417 & 0.229 & 0.271 \\
Panipat & 0.250 & 0.208 & 0.500 & 0.000 & 0.125 \\
Sonipat & 0.208 & 0.000 & 0.042 & 0.000 & 0.042 \\
Rohtak & 0.208 & 0.000 & 0.417 & 0.042 & 0.125 \\
Yamuna & 0.167 & 0.000 & 0.625 & 0.042 & 0.083 \\
Nagar & & & & \\
Jhajjar & 0.167 & 0.083 & 0.542 & 0.000 & 0.000 \\
Palwal & 0.167 & 0.000 & 0.417 & 0.000 & 0.042 \\
Faridabad & 0.138 & 0.155 & 0.236 & 0.034 & 0.052 \\
Gurgaon & 0.125 & 0.010 & 0.125 & 0.000 & 0.000 \\
Panchkula & 0.125 & 0.125 & 0.417 & 0.042 & 0.000 \\
Ambala & 0.083 & 0.000 & 0.208 & 0.042 & 0.125 \\
Bhiwani & 0.083 & 0.000 & 0.417 & 0.000 & 0.000 \\
Rewari & 0.083 & 0.000 & 0.292 & 0.083 & 0.083 \\
Hisar & 0.042 & 0.000 & 0.542 & 0.000 & 0.000 \\
Kurukshetra & 0.000 & 0.136 & 0.182 & 0.000 & 0.000 \\
Kaithal & 0.000 & 0.000 & 0.292 & 0.000 & 0.000 \\
Karnal & 0.000 & 0.000 & 0.042 & 0.000 & 0.000 \\
Jind & 0.000 & 0.000 & 0.458 & 0.000 & 0.000 \\
Sirsa & 0.000 & 0.208 & 0.542 & 0.000 & 0.083 \\
Mahendragarh & 0.000 & 0.000 & 0.333 & 0.000 & 0.000 \\
\hline
\end{tabular}

Almost twenty one per cent of the urban households in the districts of Panipat and Sirsa were found deprived because they do not have their own house or independent house. More than thirteen per cent of the urban households in the districts of Faridabad and Kurukshetra were counted as poor regarding this indicator. While the households in the urban areas of the districts of Rohtak, Sonipat, Hisar, Jind, Kaithal, Karnal, Rewari, Bhiwani, Ambala, Fatehabad and Yamuna Nagar were counted as non-poor because they lived in their own houses or independent house.

More than fifty per cent of the urban households in the districts of Yamuna Nagar, Jhajjar, Sirsa, Hisar and Sonipat do not have cemented or pucca floor and used a floor made by mud, bamboo, wood, plank or other low quality material. The urban households in the district of Karnal and Sonipat with 4.2 per cent of households were found to be slightly deprived in reference to this indicator followed by the districts of Mewat (13.9\%), Faridabad (23.6\%) and Rewari (29.2\%).

The Table 4 also showed the deprivation levels of the urban households in Haryana in reference to the wall type attribute. It was found that about $23 \%$ of the urban households in the district of Fatehabad were found deprived followed by the households in the district of Rewari (8.3\%). Only $4.2 \%$ of urban households in each district Rohtak, Yamuna Nagar, Ambala and Panchkula were counted as poor related to the wall type attribute. In Faridabad district, only 3.4 per cent urban families were in a state of poverty because of they were used a house, whose walls were made with mud, bamboo, plank, lime stone, wood, unbrunt bricks or other low quality materials. On the other hand, the urban families in the districts of Gurgaon, Hisar, Kurukshetra, Jind, Karnal and Kaithal and in all other remaining districts counted as non-deprived because they have a pucca or cemented house walls. On the analysis of deprivation levels of roof type, twenty seven per cent of the urban families in the district of Fatehabad were stated as poor. More than twelve per cent of the urban households in the districts of Panipat, Ambala and Rohtak were also found poor regarding this indicator. On the other hand, the families from urban areas in the districts of Panchkula, Gurgaon, Hisar, Kurukshetra, Kaithal, Jind, Mahendragarh, Jhajjar and Bhiwani were found to be slightly deprived related to the roof type indicator.

\section{District-wise aspect based multidimensional poverty in the urban areas of Haryana}

Now we turn to discuss the multidimensional poverty in the urban areas of the districts of Haryana. Table 5 presents the estimates of districtwise multidimensional headcount ratios $(\mathrm{H})$, the average intensity (A) and multidimensional poverty 
C) Tanwar et al.

index (MPI) on the aspect of drinking water, sanitation and housing facilities in urban areas of the districts of Haryana.

Table 5: Estimates of district-wise multidimensional poverty index (MPI) on the aspect of drinking water, sanitation and housing facilities in urban Haryana

\begin{tabular}{ccccc}
\hline Districts & H & A & MPI & Rank \\
\hline Mewat & 0.854 & 0.427 & 0.365 & 1 \\
Fatehabad & 0.833 & 0.355 & 0.296 & 2 \\
Rohtak & 0.417 & 0.460 & 0.192 & 3 \\
Mahendragarh & 0.500 & 0.358 & 0.179 & 4 \\
Jhajjar & 0.356 & 0.460 & 0.164 & 5 \\
Ambala & 0.583 & 0.257 & 0.150 & 6 \\
Bhiwani & 0.396 & 0.374 & 0.148 & 7 \\
Panipat & 0.542 & 0.262 & 0.142 & 8 \\
Sirsa & 0.458 & 0.300 & 0.137 & 9 \\
Yamuna Nagar & 0.292 & 0.400 & 0.117 & 10 \\
Kaithal & 0.250 & 0.383 & 0.096 & 11 \\
Hisar & 0.167 & 0.550 & 0.092 & 12 \\
Rewari & 0.250 & 0.350 & 0.088 & 13 \\
Sonipat & 0.208 & 0.420 & 0.087 & 14 \\
Palwal & 0.167 & 0.425 & 0.071 & 15 \\
Kurukshetra & 0.250 & 0.267 & 0.067 & 16 \\
Faridabad & 0.136 & 0.200 & 0.027 & 17 \\
Gurgaon & 0.042 & 0.400 & 0.017 & 18 \\
Jind & 0.083 & 0.200 & 0.017 & 19 \\
Karnal & 0.000 & 0.000 & 0.000 & 20 \\
Panchkula & 0.000 & 0.000 & 0.000 & 21 \\
\hline & & & &
\end{tabular}

Table 5 revealed that the MPI values vary from zero in Panchkula and Karnal districts to a high of 0.365 in the Mewat district. The urban households in the district of Mewat had the highest MPI value i.e. 0.365 followed by the districts of Fatehabad, Rohtak, Mahendragarh, Jhajjar and Ambala indicating high level of deprivation on ranking all districts in ascending order on the basis of their MPI values. On the other hand, the urban households in the districts of Panchkula and Karnal had MPI value equal to zero followed by the districts of Jind (0.083), Gurgaon (0.042) and Faridabad (0.136) and hence are slightly deprived according to the aspect based multidimensional poverty index. These districts also have the lower multidimensional poverty headcount among all the districts in the state of Haryana. According to multidimensional headcount ratio, it was found that in the urban areas of the districts of Mewat almost 85.4 per cent households were found as multidimensionally poor. This means that the households in Mewat are in acute poverty and deprived in at least one of the attributes of a single aspect or in a mixture of attributes from all the aspects such as being in a household with no clean water, a dirt floor, unimproved sanitation facilities and poor housing conditions.

The contribution of the households that is counted as multidimensionally poor adjusted by the intensity of the deprivation experienced is indicated by the values of MPI in Table 5. The adjustment is necessary because if we only look at multidimensionally headcount ratio $(\mathrm{H})$ then it is merely known that 85.4 per cent of the households in the district of Mewat were poor. The average intensity of poor households in the Mewat district is 0.427 . It means the households are deprived in 42.7 per cent of the weighted attributes. Fatehabad is the second district whose urban households were found maximum multidimensionally poor according to multidimensional headcount ratio. According to $\mathrm{H}$, it was found that 83.3 per cent urban households in the districts of Fatehabad were counted as multidimensionally poor.

If each household was deprived in all the attributes then the value of MPI would be 1.0. For the urban households in the district of Mewat, the 85.4 per cent of households were multidimensionally poor in all the attributes. But these households are on an average deprived in 42.7 per cent of the weighted attributes, that the urban households in the Mewat district were deprived in 36.5 per cent of the total potential deprivations it could experience overall.

Similarly, 83.3 per cent of urban households in Fatehabad district were multidimensionally poor in all the attributes. But these households were on an average deprived in 35.5 per cent of the weighted attributes, that the urban households in the Fatehabad district were deprived in 29.6 per cent of the total potential deprivations it could experience overall. The urban households in the districts of Panchkula and Karnal were found completely nondeprived according to aspect based MPI approach.

\section{CONCLUSION}

The non-monetary aspects such as drinking water facilities, sanitation facilities and housing conditions are very important for measuring aspect based multidimensional poverty. District level poverty 
estimates indicates wide range of variation in indicators selected from different aspects across urban areas in Haryana. The performance of districts on the indicators related to the aspects of drinking water, sanitation facilities and housing conditions has wide variations. The urban households of the district of Mewat followed by the districts of Jhajjar, Bhiwani, Jind and Kaithal are found poor regarding drinking water facilities. In case of facilities related to sanitation, the maximum proportion of the poor urban households was found in the districts of Mewat, Mahendragarh and Bhiwani. The districts of Mewat, Fatehabad, Panipat, Sirsa, Yamuna Nagar and Jhajjar have the maximum proportion of poor families on the aspect of housing conditions. The households in urban areas in the district of Mewat followed by the districts of Fatehabad, Rohtak, Mahendragarh and Jhajjar were found multidimensionally poor as indicated by the high MPI values. The MPI can be used as an analytical tool to identify the most vulnerable people, show aspects in which they are deprived and help to reveal the interconnections among deprivations. This can enable policy makers to target resources and design policies more effectively.

\section{ACKNOWLEDGMENTS}

This research was supported by University Grants Commission (UGC). We thank our colleague Kavalpreet Kaur from department of Economics, Punjab University, Chandigarh, who provided insight and expertise that greatly assisted the research. We give a special thanks to Dr. B.K. Hooda (Professor, Statistics), who was the main supervisor of this research and managed statistical analyses of the research. We thank Ekta Hooda and P.K. Nimbrayan for their management of literature searches and comments that greatly improved the manuscript.

\section{REFERENCES}

Alkire, S. and Foster, J. 2011. Counting and multidimensional poverty measures. Journal of Public Economics, 95: 476-87.

Alkire, S., Foster, J.E., Seth, S., Santos, M.E., Roche, J.M. and Ballon, P. 2015. Multidimensional poverty measurement and analysis, Oxford University Press, Oxford.

Dagum, C. 1989. Poverty as perceived by the Leyden evaluation project: A survey of Hagenaars' contribution on the perception of poverty. Economic Notes, 1: 99-110.

Haagenars, A.J.M. 1986. The perception of poverty. North Holland, Amsterdam.

Mohanty, S.K. 2011. Multidimensional poverty and child survival in India. PLoS ONE 6(10). doi. e26857.

Mohanty, S.K. 2012. Multiple deprivation and maternal care in India. International Perspective on Sexual and Reproductive Health, 38(1): 6-14.

NSSO. 2013. Key indicators on drinking water, sanitation, hygiene and housing condition in India, 69th round, Government of India.

Sen, A. 1992. Inequality Re-examined. Russell Sage Foundation: New York.

Sen, A.K. 1985. Commodities and capabilities. North Holland: Elsevier, Amsterdam.

Sharma, L. and Vashishth, M. 2017. Level of deprivation and poverty patterns in Haryana: A district wise analysis, International Journal of Advanced Education and Research, 2(3): 227-235.

Srivastava, A.K. 2009. Some aspects of estimating poverty at small area. Journal of Indian Society of Agricultural Statistics, 63(1): 1-23.

Strotmann, H. and Volkert, J. 2018. Multidimensional poverty index and happiness. Journal of Happiness Studies, 19: 167-189.

Subhasis De and Datta, K. 2014. Multidimensional poverty index of Totos- The smallest and primitive tribe in jalpaiguri district of West Bengal. Economic Affairs, DOI: 10.5958/0976-4666.2014.00032.1.

Tanwar, N. and Hooda, B.K. 2017. Estimation of aspect based multidimensional poverty in rural Haryana. Advances in Research, 10(5): 1-8.

WHO. 1948. Constitution of the World Health Organization. http://www.whoint/governance/eb/who-constitution_ en.pdf. 
